\title{
Radial force cancellation of bearingless brushless direct current motor using integrated winding configuration
}

\author{
Ali A. Yousif, Ahmed M. Mohammed, Mohammed Moanes E. Ali
}

Department of Electrical Engineering, University of Technology, Baghdad, Iraq

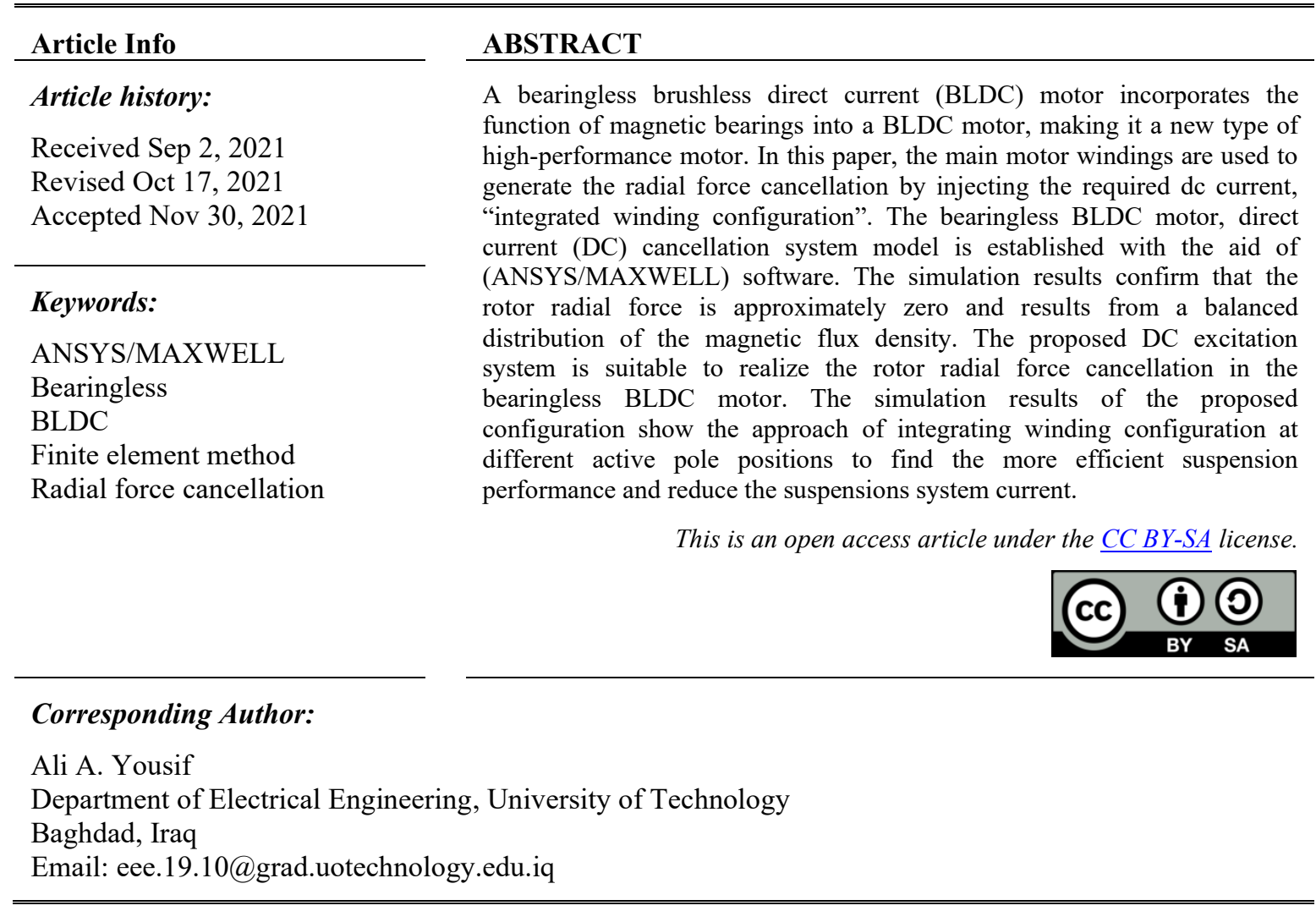

\section{INTRODUCTION}

Bearingless motors are a modern version of electric motors for high-speed applications. The main function of bearingless motors operation is the radial force. It is very important to make this force balance in all rotor positions. There are two main techniques for radial force cancelation, these are: separated winding configuration and integrated winding configuration. The second one is covered in this work, in which the torque winding and suspension force windings are combined in the same stator slots to generate simultaneously the electromagnetic torque and radial suspension force [1].

In comparison with a magnetic bearing machine, bearingless motors feature shorter rotor shafts and more incredible critical speeds and they are suitable for super high-speed applications due to the advantages of low friction losses, no lubrication need, no vibration noise, and long life [2]-[4]. Bearingless machines solve the limitations of axial length, large-volume motors, complex system structure, and the high cost of pure magnetic bearings. The main challenge of these machines is the rotor radial force which creates magnetic pull-out force and vibration, especially at high-speed rotation, resulting in extra mechanical losses and bearing reliability degradation; therefore, the resultant radial force of the rotor must be minimized or canceled to zero at the equilibrium position for rotational motion [5]-[7]. The interaction between the rotor magnets and the stator armature core are the main sources of the radial force. The radial force disappears when the symmetric stator is designed with an even number of stator slots [5]. In an integrated winding configuration, the cancellation current and the motor current are passing through the same winding in the stator slots. So that, the distribution of air-gap flux density results from the magnetic flux of the suspension 
current and the motor torque current is symmetric. As a result, a force of levitation is created. The rotor shaft is suspended in the air gap without mechanical contact, and the rotor rotates without hitting the bearing surface [8], [9].

The applications of bearingless brushless direct current (BLDC) motors have been extensively researched in many fields, such as blood pumps [10], Flywheel energy storage [4]. The rotor radial force can be minimized by selecting the proper slot/pole combination. The most common divisor (MCD) is the main indication for the required slot/pole combination. A higher even MCD number gives a higher number of symmetrical sectors for the machine, and as a result, a balance radial force with a lower magnitude will obtain [5], [11], [12]. In this paper, integrated winding configuration has been implemented with a 12/8 slot/pole combination. The radial force has been analyzed and calculated to find the required generated force for radial force cancellation in the motor.

The most recent studies about bearingless BLDC motor. Qin and Zhu [13] introduces the mathematical model of levitation forces, which shows that the levitation forces are independent of the torque. To reduce cogging torque and increase motor performance, adjustments are carried out for its primary parameters. The torque and levitation forces can be designed independently and controlled with the high precision control system. In addition, the bearingless BLDC's basic structure and operation concept are analyzed in detail. Tu et al. [14] introduces the composition of an inner stator winding for levitation force and outer stator windings for the torque. The mathematical model of the levitation forces is deduced, and the optimizations are carried for its main parameters to minimize the cogging torque and improve the motor performance. The simulation results confirm that the motor has superior decoupling characteristics compared with the double-winding motor.

This paper aimed to analyze and calculate the cancelation of radial forces results from unbalanced air gap flux density distribution, the eccentricity rotor condition, and high-speed of the rotation. Therefore, the resultant radial force of the rotor must be approximately equal to zero at the center (normal) position for the rotational movement speed where using integrated winding configuration by generating direct current (DC) to radial forces cancellation. This integrated winding configuration is used to generate the torque and suspension force of the motor has the advantage of more efficient suspension performance and reduce the current, is less expensive, and the cancellation radial force distribution is better than suspension fixed coils. The article is organized as follows: section 2 introduces the radial force calculation. Section 3 presents a technique of the cancellation radial force. Section 4 illustrates the results, and section 5 summarizes the conclusion.

\section{CALCULATION OF RADIAL FORCE}

In the electrical motors, appearance of the radial force is associated with the generation of electromagnetic torque. In bearingless motor applications, cancelation of the radial force requires calculating the radial forces that affect the motor rotor [15]. The magnitude and direction of radial forces is highly dependent on the position of the rotor inside the air gap, therefore it is necessary to evaluate the length of the air gap at eccentricity condition.

\subsection{Analytical calculation of radial force}

Maxwell's stress tensor principle is used to calculate the magnetic forces or torque for any electrical machine. The idea is based on Faraday's assertion according to which stress happens in the flux lines. The tangential and normal components of the flux density can be obtained. With the Maxwell stress method, normal and tangential flux density components must be known in all points along the closed line in the air gap, and the tangential and normal forces at each point in the air gap region have been calculated using (1) and (2). The components of stress are based on field components.

$$
\begin{aligned}
& f_{t}=\frac{1}{\mu_{0}}\left(B_{t}\right)\left(B_{n}\right) \\
& f_{n}=\frac{1}{2 \mu_{0}}\left[\left(B_{n}\right)^{2}-\left(B_{t}\right)^{2}\right]
\end{aligned}
$$

where $f_{t}$ and $f_{n}$ are normal and tangential force density $(\mathrm{N} / \mathrm{m})$ respectively, $B_{n}$ and $B_{t}$ are normal and tangential flux densities (tesla). The total normal and tangential forces value can be calculated from (3), (4) along the air gap line. Specifically, the overall normal and tangential force/length at a single rotor position can be expressed as:

$$
F_{t}=\frac{P}{2} \int_{0}^{2 \pi} f_{t}\left(\varphi_{r}\right) l R_{c} d \varphi_{r}
$$




$$
\mathrm{F}_{\mathrm{n}}=\frac{\mathrm{P}}{2} \int_{0}^{2 \pi} \mathrm{f}_{\mathrm{n}}\left(\varphi_{\mathrm{r}}\right) \operatorname{lR} \mathrm{c} \mathrm{d} \varphi_{\mathrm{r}}
$$

where $\mathrm{P}$ is a number of poles, $l$ is the axial length of the machine $(\mathrm{mm})$, and $R_{c}$ is the radius of the contour $(\mathrm{mm})$. The following relationship can calculate the total torque production:

$$
\mathrm{T}=\frac{1}{\mu_{0}} \int_{\mathrm{s}}\left[(\mathrm{r} \times \mathrm{B})(\mathrm{B} \cdot \mathrm{n})-\frac{1}{2} \mathrm{~B}^{2}(\mathrm{r} \times \mathrm{n})\right] \mathrm{ds}
$$

where $\mathrm{B}$ is the flux density vector (tesla), $\mathrm{n}$ is the normal unit vector in the elements, $\mathrm{r}$ is the rotor radius $(\mathrm{mm}), d s$ is the surface of the element, and $\mu_{\circ}$ is the magnetic permeability $(\mathrm{H} / \mathrm{m})[16]-[18]$.

\subsection{Variation of air gap length under rotor eccentricity condition}

Figure 1 shows the resultant radial force under rotor eccentricity conditions. The magnitude and direction of the resultant radial forces result in the direction of $\theta$. Assume the normal distance between the rotor and stator bore is $g_{0}$. If the rotor moves from the stator center are $\mathrm{x}$ and $\mathrm{y}$, the air gap length $g$ at eccentricity is (6):

$$
\mathrm{g}=\mathrm{g}_{0}-\mathrm{x} \cos \left(\varphi_{\mathrm{s}}\right)-\mathrm{y} \sin \left(\varphi_{\mathrm{s}}\right)
$$

The calculation of the air gap permeance $\mathrm{P}_{0}$ at an angular position $\varphi_{s}$ is (7):

$$
P 0\left(\varphi_{\mathrm{s}}\right)=\frac{\mu_{0} \mathrm{Rl}}{\mathrm{g}_{0}}\left(1+\frac{\mathrm{x}}{\mathrm{g}_{0}} \cos \varphi_{\mathrm{s}}+\frac{\mathrm{y}}{\mathrm{g}_{0}} \sin \varphi_{\mathrm{s}}\right)
$$

where $\mathrm{R}$ is the rotor radius [19], [20].

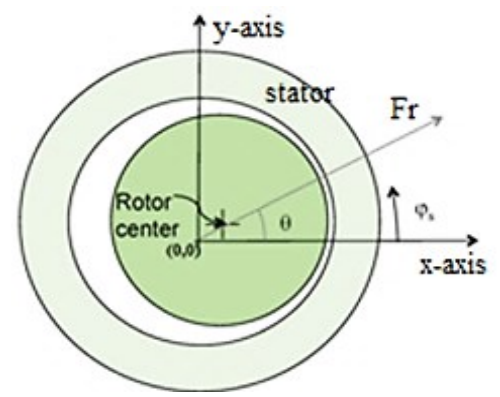

Figure 1. Rotor eccentricity with air gap length variation

\section{RADIAL FORCE CALCULATION METHOD}

The rotational radial force can be controlled by generating an opposite force or "cancellation force". This cancellation force can be controlled by controlling a DC excitation current in each pole independently. Furthermore, because radial force is a function of rotor position, radial force management necessitates varying the excitation current and polarity with rotor position [21]. This paper proposes a DC excitation scheme for the radial force control of the 12/8 pole bearingless BLDC for blood pump application. By proper distribution of the pole's current in the exciting windings, the required DC can be produced for radial force cancelation.

In integrating winding configuration, one coil is employed in each slot to generate torque and suspension force. For the motor torque generation, the machine has been supplied by a 3-phase current source. Figure 2 shows the three-phase winding connection sequence. The suspension current is supplied by a DC excitation source. In such configuration, the accuracy is higher, more efficient suspension performance, and the cancellation radial force distribution is better than a separated winding configuration [22]-[24].

Two methods have been used to cancel the radial forces. The first method is the use of foursuspension poles, the second is the use of all-suspension poles to cancel the radial forces and to get a balanced suspension rotor in the air gap. Figure 3(a) shows the first method, of 12/8 poles bearingless BLDC motor for radial force cancellation using four-poles to produce the suspension forces. Only the coils of the pole $(1,4,7,10)$ are active for DC exciting current, and it is assumed that the currents in all coils in the (12) stator poles can be controlled independently. Let the coils of phase $\mathrm{C}$ be used for the DC exciting current. Where the poles currents are $i_{c 1}, i_{c 2}, i_{c 3}$, and $i_{c 4}$ respectively, and $\theta_{r}$ is the rotor angle. The step rotation angle of this bearingless BLDC is (22.5) mechanical rotor degrees to obtain results with change D.C polarity every step. The radial force in the BLDC motor is analyzed by taking the force generated with one pole. The 
overlap area, as well as the non-overlap area of the stator tooth the flux passes through them because of the fringing effect as shown in Figure 3(b). The radial force in the motor can be analyzed by considering the force generated with a four-poles. The inductance can be expressed as (8),

$$
\mathrm{L}_{\mathrm{C}}=\frac{\mu_{0} \mathrm{~N}^{2} l \mathrm{lR} \theta_{\mathrm{o}}}{2\left(\mathrm{l}_{\mathrm{g}}+\mathrm{l}_{\mathrm{m}}\right)}+\mathrm{N}^{2} \mathrm{~K}_{\mathrm{f}} \theta_{\mathrm{no}}
$$

where $\mu_{0}$ is the permeability of air, $\mathrm{N}$ is the number of coil turn, $K_{f}$ is a constant for the fringing inductance, $l_{g}$ is the air gap length, $l_{m}$ is the permanent magnet thickness, $\theta_{o}$ and $\theta_{n o}$ are the overlapping and the nonoverlapping angle, respectively. The radial force $F_{C 1}$ and torque $T_{C 1}$ in one pole can be expressed as (9).

$$
\begin{aligned}
& F_{C 1}=\frac{1}{2} i^{2}{ }_{C 1} \frac{d L_{c}}{d x} \\
& \mathrm{~T}_{\mathrm{C} 1}=\frac{1}{2} \mathrm{i}^{2}{ }_{\mathrm{C} 1} \frac{\mathrm{dL} \mathrm{L}_{\mathrm{c}}}{\mathrm{d} \theta_{\mathrm{o}}}
\end{aligned}
$$

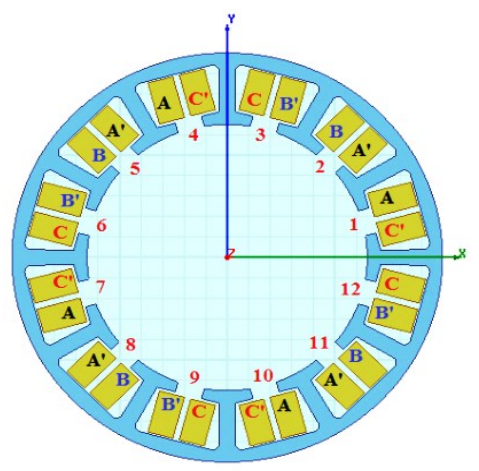

Figure 2. Geometry and winding configuration motor torque of the BLDC motor

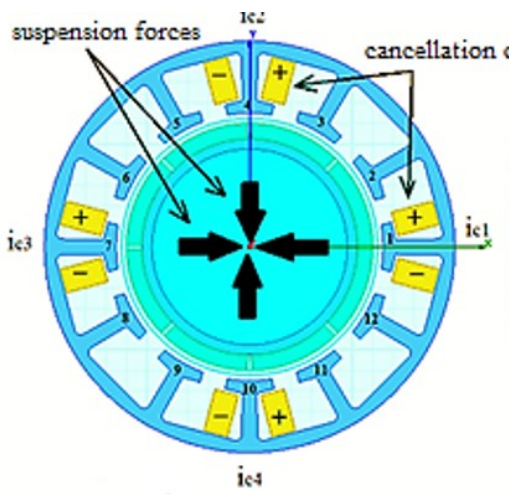

(a)

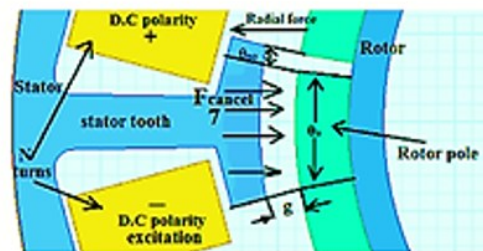

(b)

Figure 3. Four-suspension poles of bearingless BLDC motor (a) Overview and (b) pole (C3)

Since $\left(l_{g}+l_{m}\right)$ is fixed, by neglecting the fringing flux $F_{C 1}$ can be simplified as (11),

$$
\mathrm{F}_{\mathrm{C} 1} \approx \frac{1}{2} \mathrm{i}^{2}{ }_{\mathrm{C} 1} \frac{\mathrm{L}_{\mathrm{C}}}{\left(\mathrm{l}_{\mathrm{g}}+\mathrm{l}_{\mathrm{m}}\right)}=\frac{\mu_{0} \mathrm{~N}^{2} \mathrm{lR} \theta_{\mathrm{o}}}{2\left(\mathrm{l}_{\mathrm{g}}+\mathrm{l}_{\mathrm{m}}\right)^{2}} \cdot \mathrm{i}^{2}{ }_{\mathrm{C} 1} \approx \mathrm{K}_{\mathrm{F}} \mathrm{i}^{2} \mathrm{C} 1
$$

where $K_{F}=\frac{\mu_{0} \cdot N^{2} l R \theta_{o}}{2\left(l_{g}+l_{m}\right)^{2}}[21]$. In (11) shows that the radial force's capacity is approximately proportional to the square of the DC excitation and inversely proportional to the squared air gap length. It's also influenced by rotor angle. The total radial forces are equal to the vector summation of the forces produced by all the exciting poles. Note that for each pole the direction of the radial force depends on the polarity of the D.C excitation [19], [21]. The resultant radial force in the $\mathrm{x}$-and $\mathrm{y}$-axis is: 


$$
\begin{aligned}
& \mathrm{F}_{\mathrm{X}} \approx \mathrm{F}_{\mathrm{C} 1} \pm \mathrm{F}_{\mathrm{C} 3}=\mathrm{K}_{\mathrm{F}}\left(\mathrm{i}^{2}{ }_{\mathrm{C} 1} \pm \mathrm{i}^{2}{ }_{\mathrm{C} 3}\right) \\
& \mathrm{F}_{\mathrm{y}} \approx \mathrm{F}_{\mathrm{C} 2} \pm \mathrm{F}_{\mathrm{C} 4}=\mathrm{K}_{\mathrm{F}}\left(\mathrm{i}^{2}{ }_{\mathrm{C} 2} \pm \mathrm{i}^{2}{ }_{\mathrm{C} 4}\right)
\end{aligned}
$$

The second method, integrating winding configuration shown in Figure 4, the all-suspension poles are using to cancellation by the same principle of four-suspension poles equations but all poles are active that requires minimum consumption cancellation DC and more efficient suspension performance and accuracy.

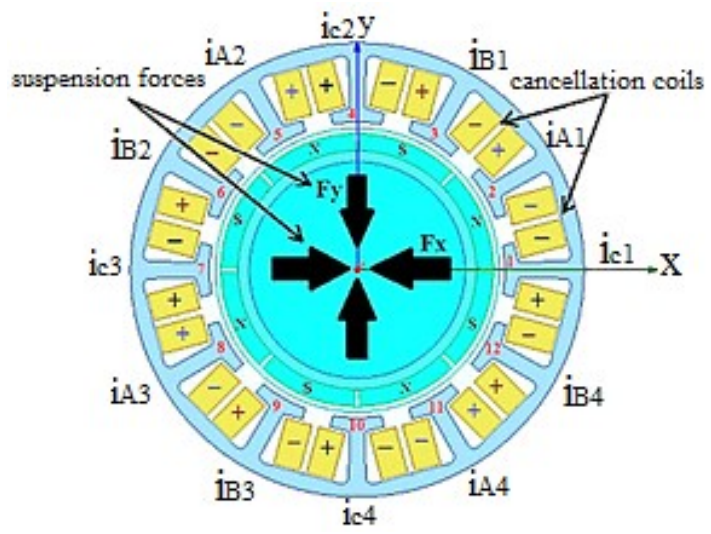

Figure 4. All-suspension poles method

\section{RESULTS AND DISCUSSION}

To effectively verify the integrated winding configuration, a BLDC blood pump bearingless motor is simulated and analyzed by using (ANSYS/MAXWELL) software. The main parameters of the bearingless motor are listed in Table 1 [25]. The instantaneous and R.M.S values of the generated torque are shown in Figure 5. The waveform of the 3-phase stator current with R.M.S values is shown in Figure 6. During one rotation cycle, to analyze the distribution of radial forces of the motor, 2-D analysis is performed every (22.5) mechanical degree.

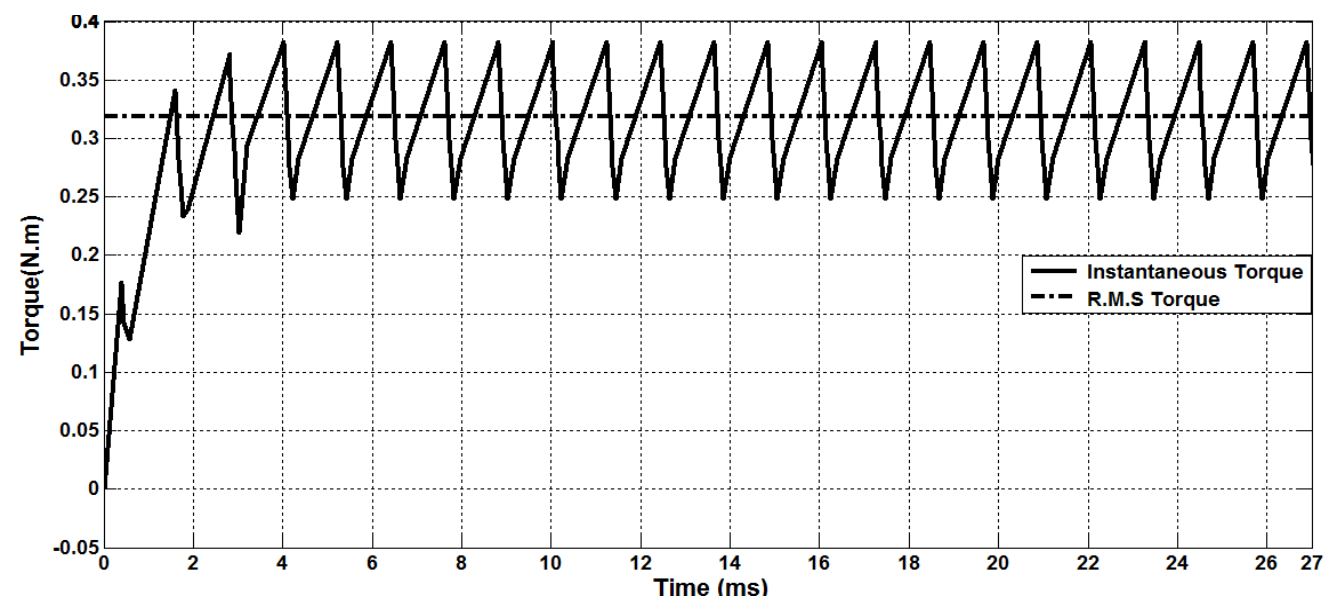

Figure 5. Instantaneous and R.M.S torque

Table 1. BLDC motor parameters [25]

\begin{tabular}{lccc}
\hline \multicolumn{1}{c}{ Parameters } & value & Parameters & value \\
\hline Number of phases & 3 & Stator inner diameter & $26 \mathrm{~mm}$ \\
No-load speed & $750 \mathrm{rpm}$ & No. of poles & 8 \\
Axial length & $10 \mathrm{~mm}$ & Pole embrace & 0.95 \\
Air gap length & $1 \mathrm{~mm}$ & PM thickness & $1.5 \mathrm{~mm}$ \\
No. of slots & 12 & Rotor outer diameter & $24 \mathrm{~mm}$ \\
Stator outer diameter & $40 \mathrm{~mm}$ & Rotor inner diameter & $19 \mathrm{~mm}$ \\
\hline
\end{tabular}



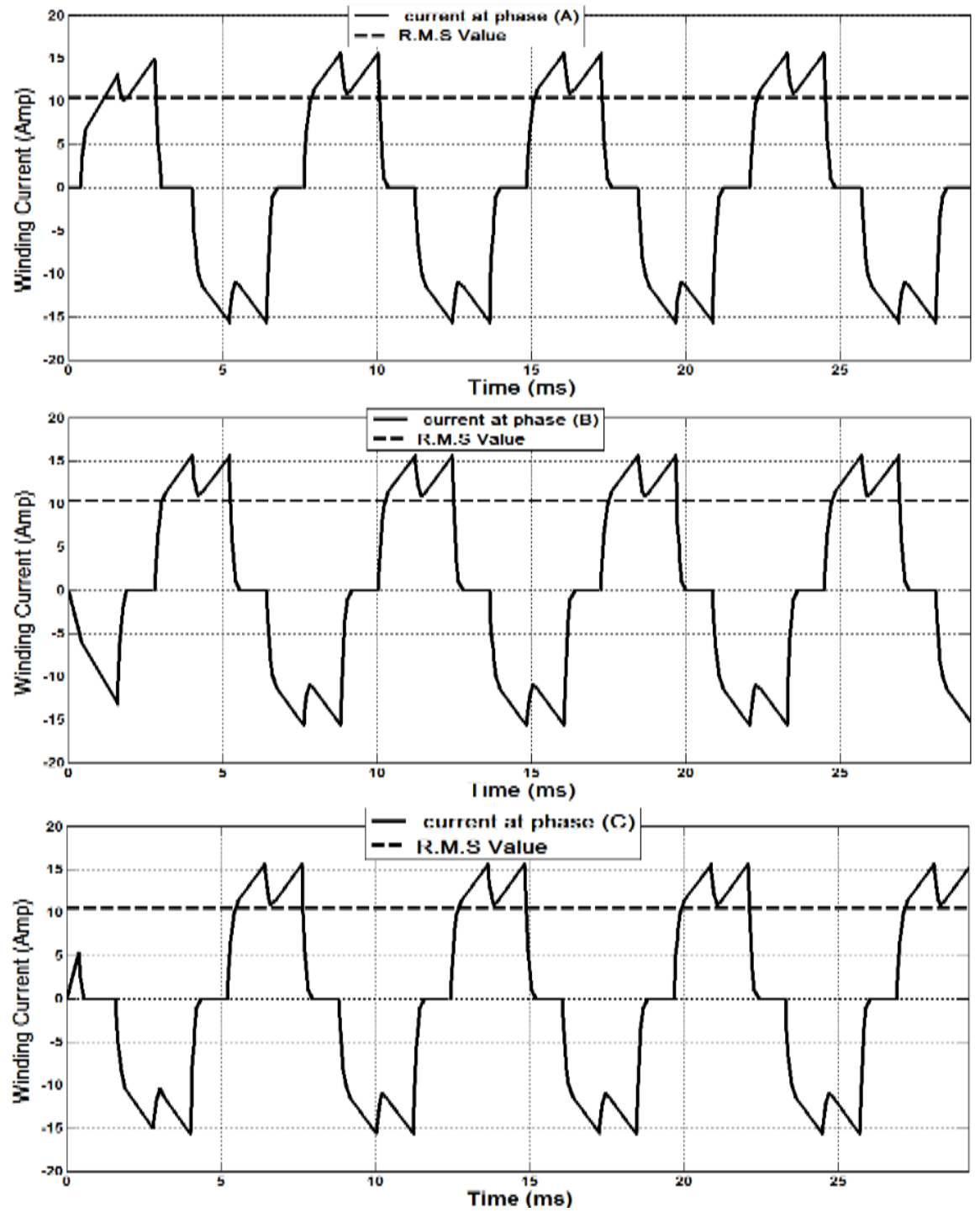

Figure 6. 3-phase stator current waveform

\subsection{Cancellation of radial force by using four-suspension poles}

The suspension action here is performed by using only four-suspension poles, the axis of one pair of these poles is perpendicular to the axis of the other two poles. Now, by exciting each pair of the pole by appropriate DC current, the radial force is canceled to be about zero. When the rotor is positioned at the motor center and rotated by one cycle, Figure 7 shows the radial force without and with the suspension effect. The currents of the two-suspension pair of poles which required to cancel the radial force are listed in Table 2. Noted that the maximum value for cancellation current is (2.95) Ampere in coil $(1,7)$ and (2.55) Ampere in coil $(4,10)$.

Table 2. DC excitation of four-suspension poles (the rotor at center)

\begin{tabular}{|c|c|c|c|c|c|}
\hline $\begin{array}{c}\text { Rotor rotating } \\
\text { mechanical angle(degree) }\end{array}$ & $\begin{array}{c}\mathrm{I}_{\mathrm{coil}(1,7)} \\
(\mathrm{A})\end{array}$ & $\begin{array}{c}\mathrm{I}_{\mathrm{coil}(4,10)} \\
(\mathrm{A})\end{array}$ & $\begin{array}{c}\text { Rotor rotating } \\
\text { mechanical angle(degree) }\end{array}$ & $\begin{array}{c}\mathrm{I}_{\text {coil }(1,7)} \\
(\mathrm{A})\end{array}$ & $\begin{array}{c}\mathrm{I}_{\operatorname{coil}(4,10)} \\
(\mathrm{A})\end{array}$ \\
\hline 22.5 & 0.11 & 0.07 & 202.5 & -0.01 & -0.12 \\
\hline 45 & 2.95 & 0.95 & 225 & 1.55 & 2.55 \\
\hline 67.5 & -0.1 & -0.06 & 247.5 & -0.11 & 0.06 \\
\hline 90 & -2.95 & -0.95 & 270 & -1.85 & -2.5 \\
\hline 112.5 & -0.05 & 0.03 & 292.5 & 0.14 & -0.09 \\
\hline 135 & 2.95 & 2.55 & 315 & 1.55 & 1 \\
\hline 157.5 & -0.02 & 0.01 & 337.5 & -0.12 & 0.055 \\
\hline 180 & -3.1 & -2.55 & 360 & -1.98 & -1.25 \\
\hline
\end{tabular}


When the rotor is located at $(0.1,0) \mathrm{mm}$ away from the motor center in the $\mathrm{x}$-direction, Figure 8 shows the radial force values without and with the suspension effect. The currents of the two-suspension pair of poles which required to cancel the radial force are listed in Table 3 . The maximum value for cancellation current is (751.7) Ampere in coil $(1,7)$ and (453.5) Ampere in coil $(4,10)$.
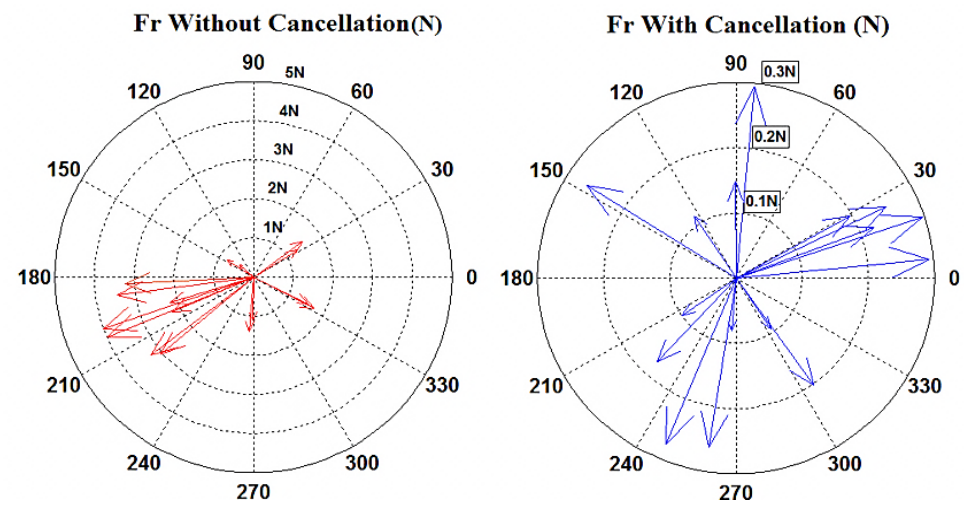

Figure 7. Radial force vectors without and with cancellation by using four-suspension poles (the rotor at the center position)

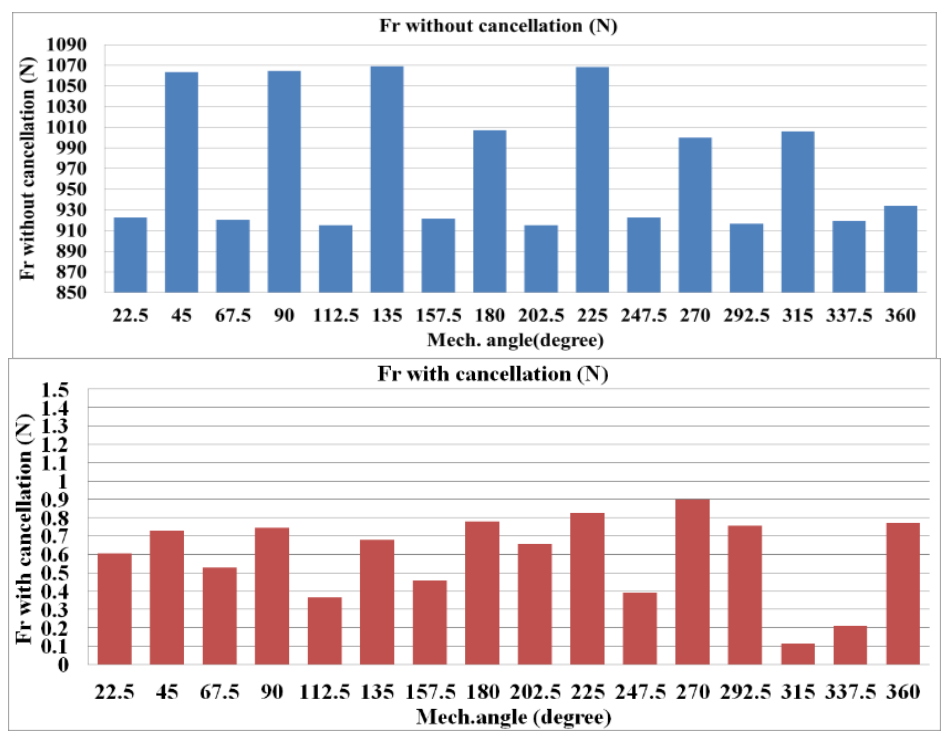

Figure 8 . Radial force values by using four-suspension poles, the rotor position is $(0.1,0) \mathrm{mm}$

Table 2. DC excitation values of four-suspension poles, rotor position is $(0.1,0) \mathrm{mm}$

\begin{tabular}{cccccc}
\hline $\begin{array}{c}\text { Rotor rotating } \\
\text { mechanical angle (degree) }\end{array}$ & $\begin{array}{c}I_{\text {coil(1,7) }}(\mathrm{A}) \\
I_{\text {coil }(4,10)}\end{array}$ & $\begin{array}{c}\text { Rotor rotating } \\
\text { mechanical angle (degree) }\end{array}$ & $\begin{array}{c}I_{\text {coil }(1,7)} \\
(\mathrm{A})\end{array}$ & $\begin{array}{c}I_{\text {coil }(4,10)} \\
(\mathrm{A})\end{array}$ \\
\hline 22.5 & 71 & -39.6 & 202.5 & 72.8 & -42.9 \\
45 & -748 & 452.6 & 225 & 770 & -430 \\
67.5 & -72.8 & 43.5 & 247.5 & -73 & 43.5 \\
90 & 757 & -452.2 & 270 & 750.5 & -451 \\
112.5 & 72.6 & -43 & 292.5 & 72.7 & -43 \\
135 & -750.5 & 449 & 315 & -751 & 452 \\
157.5 & -73 & 43.2 & 337.5 & -73 & 42.9 \\
180 & 751 & -451.2 & 360 & 751.7 & -453.5 \\
\hline
\end{tabular}

\subsection{Cancellation of radial force by using all-suspension poles}

The suspension action here is performed by using all-poles. Now, by exciting each pair of the pole by appropriate DC current, the radial force can be reduced to about zero. When the rotor is located at $(0.1,0)$ $\mathrm{mm}$ away from the motor center in the x-direction, Figure 9 shows the radial force without and with the suspension effect. The currents of the six-suspension pair of poles which required to cancel the radial force 
are listed in Table 4. Noted that the maximum values for cancellation current are (31) Ampere in coil $(1,7)$ and (46) Ampere in coils $(2,8),(3,9),(4,10)$, and (85) Ampere in coils $(5,11),(6,12)$.

From Figure 7, it turns out that the radial forces have low values (about zero) when the rotor is at the center. From Figure 8, it can be familiarized that as the rotor is moved away from the center, the radial force will have high values. Of course, this appears on the value of the DC excitation required to achieve the cancellation of radial force. During one rotation of the rotor, it can be seen that the radial force is variable, the maximum value of radial force occurs when the rotor poles face the stator teeth. Therefore, the cancellation current must be changed accordingly.

From Figure 7, it turns out that the radial forces have low values (about zero) when the rotor is at the center. From Figure 8, it can be familiarized that as the rotor is moved away from the center, the radial force will have high values. Of course, this appears on the value of the DC excitation required to achieve the cancellation of radial force. During one rotation of the rotor, it can be seen that the radial force is variable, the maximum value of radial force occurs when the rotor poles face the stator teeth. Therefore, the cancellation current must be changed accordingly.

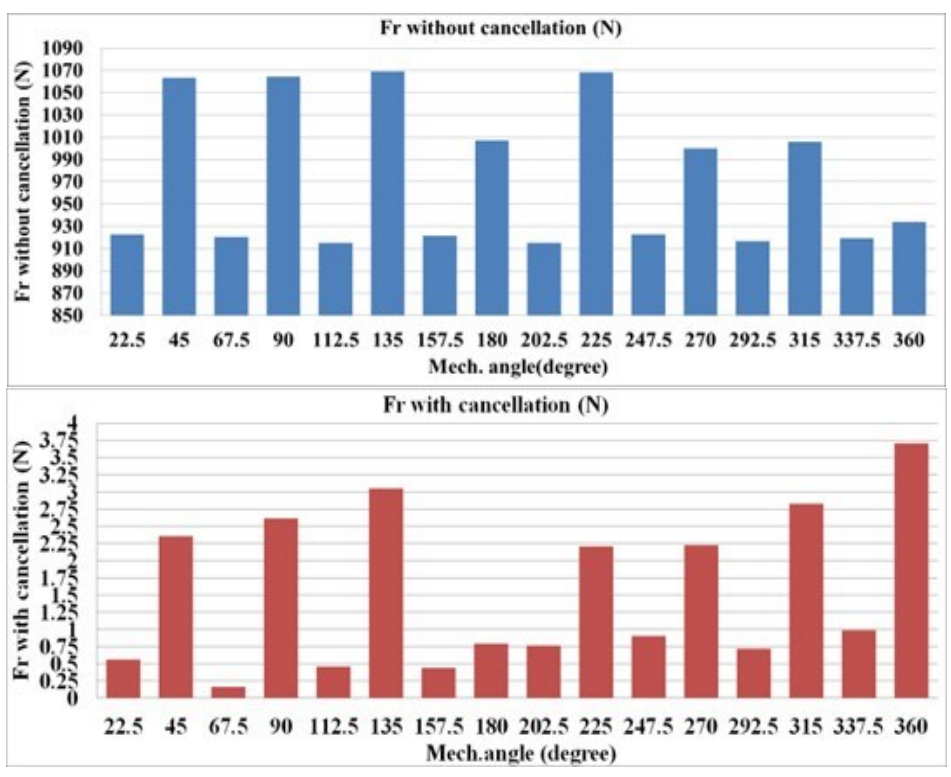

Figure 9. Radial force values by using all-suspension poles, the rotor position is $(0.1,0) \mathrm{mm}$

Table 4. DC excitation values of all-suspension poles, rotor position is $(0.1,0) \mathrm{mm}$

\begin{tabular}{ccccccc}
\hline $\begin{array}{c}\text { Rotor rotating } \\
\text { mechanical angle (degree) }\end{array}$ & $\begin{array}{c}\mathrm{I}_{\text {coil (1,7) }}(\mathrm{A}) \\
22.5\end{array}$ & $\begin{array}{c}\mathrm{I}_{\text {coil (5,11) }}(\mathrm{A}) \\
45\end{array}$ & $\begin{array}{c}\mathrm{I}_{\text {coil (6,12) }} \\
(\mathrm{A})\end{array}$ & $\begin{array}{c}\mathrm{I}_{\text {coil (2,8) }} \\
(\mathrm{A})\end{array}$ & $\begin{array}{c}\mathrm{I}_{\text {coil (3,9) }} \\
(\mathrm{A})\end{array}$ & $\begin{array}{c}\mathrm{I}_{\text {coil }(4,10)} \\
(\mathrm{A})\end{array}$ \\
\hline 67.5 & 0 & -41.9 & 41.9 & -41.9 & -41.9 & -41.9 \\
90 & -31.3 & 45 & -85 & 7 & 7 & 0 \\
112.5 & 0 & -85.3 & -46.3 & 46.3 & 46.3 & 46.3 \\
135 & 31.5 & -45.9 & 85.3 & -8.2 & -8.2 & 0 \\
157.5 & 0 & 85 & -85.9 & -45.9 & -45.9 & -45.9 \\
180 & -31.5 & 46.2 & -46.2 & 8.5 & 8.5 & 0 \\
202.5 & 0 & -85.3 & 85.25 & -8.2 & 46.2 & 46.2 \\
225 & 31.75 & -45.7 & 45.7 & -45.7 & -45.7 & -45.7 \\
247.5 & 0 & 85 & -85 & 8.2 & 8.2 & 0 \\
270 & -31.3 & 46.3 & -46.3 & 46.3 & 46.3 & 46.3 \\
292.5 & 0 & -85.3 & 85.3 & -9.5 & -9.5 & 0 \\
315 & 31.57 & -46 & 46 & -46 & -46 & -46 \\
337.5 & 0 & 85.3 & -85.3 & 8.3 & 8.3 & 0 \\
360 & -31.7 & 45.8 & -45.8 & 45.8 & 45.8 & 45.8 \\
\hline
\end{tabular}

\section{COMPARISON BETWEEN FOUR-SUSPENTION POLES AND ALL-SUSPENSION POLES TECHNIQUES}

To compare four-suspension poles and all-suspension poles techniques, Table 5 shows the DC cancellation current for different operating conditions. For all cases, the required current is less in all- 
suspension poles methods, the percentage reduction in maximum current is between $36.5 \%$ and $88.9 \%$. So, it can be said that although the all-suspension poles method is expensive and complex, it requires a power supply with a lower current rating.

Table 5. Comparison between DC currents required for cancellation

\begin{tabular}{cccccc}
\hline \multirow{2}{*}{ Rotor position $(\mathrm{mm})$} & \multicolumn{4}{c}{ DC cancellation current (A) } \\
& Rotor rotating mechanical angle (degree) & \multicolumn{2}{c}{ Four-poles suspension } & \multicolumn{2}{c}{ All-poles suspension } \\
Max. value & Min. value & Max. value & Min. value \\
\hline$(0,0)$ & 22.5 & 0.14 & 0.01 & 0.06 & 0.04 \\
$(0,0)$ & 45 & 3.1 & 0.95 & 1.4 & 0.05 \\
$(0.1,0)$ & 22.5 & 73 & 39.6 & 46.3 & 30.9 \\
$(0.1,0)$ & 45 & 770 & 430 & 85.3 & 0 \\
\hline
\end{tabular}

\section{CONCLUSION}

In this paper, the radial force of the $(12 / 8)$ bearingless BLDC motor has been analyzed. Integrated winding configuration is considered where the same coil is used to generate motoring torque and to cancel the radial force. Cancellation of radial force has been achieved by using four suspension poles and allsuspension poles. At constant motoring motor current, the simulation results show that the radial force is varied with the rotor position and rotor rotating angle. Thus, there was a need to change the suspension currents to achieve the cancellation. The integrated winding configuration was found suitable to realize the radial force cancellation. Although the all-suspension poles method requires more complex connections, supplies, and control, the results of this method show the cancellation current is significantly less than the four-pole method.

\section{REFERENCES}

[1] N. Mamat, et al., "Bearingless Permanent Magnet Synchronous Motor using Independent Control," International Journal of Power Electronics and Drive Systems (IJPEDS), vol. 6, no. 2, pp. 233-241, May 2015, doi: 10.11591/ijpeds.v6.i2.pp233-241.

[2] M. Jafarboland and A. Shirzadi, "Analytical modelling of radial suspension force in bearingless surface-mounted PM synchronous motors considering static rotor eccentricity," IET Electric Power Applications, vol. 13, no. 12, pp. 1899-1910, Aug. 2019, doi: 10.1049/iet-epa.2018.5607.

[3] M. Q. Abbas and Y. A. Yassin, "Modification of speed and current limiting performance of BLDC motor based on harmony search optimization method," Indonesian Journal of Electrical Engineering and Computer Science, vol. 18, no. 1, pp. 549-557, Apr. 2020, doi: 10.11591/ijeecs.

[4] Y. Sun, F. Yang, Y. Yuan, and Y. Huang, "Out rotor bearingless brushless DC motor for flywheel energy storage," in 2017 International Workshop on Complex Systems and Networks (IWCSN), pp. 7-12, Dec. 2017, doi: 10.1109/IWCSN.2017.8276496.

[5] N. W. Liu, K.-Y. Hung, S.-C. Yang, F. C. Lee, and C. J. Liu, "Design of High-Speed Permanent Magnet Motor Considering Rotor Radial Force and Motor Losses," Energies, vol. 13, no. 1, pp. 1-16, Nov. 2020, doi: 10.3390/en13225872.

[6] Y. C. Liu, H. Q. Zhu, and L. D. Zhu, "Suspension force control system design and simulation for bearingless brushless DC motor," in Applied Mechanics and Materials, vol. 703, pp. 250-253, Dec. 2014, doi: 10.4028/www.scientific.net/AMM.703.250.

[7] L. Chen, X. Sun, and H. Zhu, "Principle of Radial Suspension Force Generation and Control System Simulation for a Bearingless Brushless DC Motor," in Electronics and Signal Processing, ed: Springer, pp. 273-280, July 2011, doi: 10.1007/978-3-64221697-8_35.

[8] Y. Sun, F. Yang, Y. Yuan, and Y. Huang, "Control of out-rotor bearingless brushless DC motor," in 2017 32nd Youth Academic Annual Conference of Chinese Association of Automation (YAC), May 2017, pp. 624-627, doi: 10.1109/YAC.2017.7967485.

[9] T. Zhang, X. Ye, L. Mo, and Q. Lu, "Electromagnetic performance analysis on the bearingless permanent magnet synchronous motor with Halbach magnetized rotor," IEEE Access, vol. 7, pp. 121265-121274, Aug. 2019, doi: 10.1109/ACCESS.2019.2937897.

[10] R. S. Raheem, M. Y. Hassan, and S. K. Kadhim, "Simulation Design of Blood-pump Intelligent Controller Based on PID-like fuzzy logic Technique," Engineering and Technology Journal, vol. 38, no. 8, pp. 1200-1213, Aug. 2020, doi: 10.30684/etj.v38i8A.534.

[11] F. Libert and J. Soulard, "Investigation on pole-slot combinations for permanent-magnet machines with concentrated windings," in Proc. ICEM, pp. 530-535, Jan. 2004.

[12] T. Sun, J.-M. Kim, G.-H. Lee, J.-P. Hong, and M.-R. Choi, "Effect of pole and slot combination on noise and vibration in permanent magnet synchronous motor," IEEE Transactions on magnetics, vol. 47, no. 5, pp. 1038-1041, Apr. 2011, doi: 10.1109/TMAG.2010.2093872.

[13] Y. Qin and H. Zhu, "Optimal design of a multi-phase double-stator bearingless brushless direct current motor," Advances in Mechanical Engineering, vol. 9, no. 6, pp.1-11, June 2017, doi: 10.1177/1687814017705112.

[14] X. Tu, W. Bu, and Q. Zeng, "Research on the Modelling of a Single-winding Bearingless Permanent Magnet Brushless DC Motor," in Journal of Physics: Conference Series, vol. 1887, no. 1, Dec. 2021, pp.1-7, doi: 10.1088/1742-6596/1887/1/012049.

[15] S. Loginov, Y. Domracheva, V. Smirnov, and D. Fedorov, "Research of radial forces and torque of bearingless synchronous machine," in Environment. Technologies. Resources. Proceedings of the International Scientific and Practical Conference, vol. 1, June 2015, pp. 128-132, doi: 10.17770/ETR2015VOL1.217.

[16] M. Polat, E. Öksüztepe, Z. Omaç, M. Yildirim, and H. Kürüm, "Examination of radial force with Finite Element Method in Switched Reluctance Motor," in 2013 8th International Conference on Electrical and Electronics Engineering (ELECO), Nov. 2013, pp. 576-580, doi: 10.1109/ELECO.2013.6713900.

[17] J. Pyrhonen, T. Jokinen, and V. Hrabovcova, Design of rotating electrical machines: John Wiley \& Sons, pp. 1-612, Dec. 2013, doi: $10.1002 / 9780470740095$. 
[18] W. Zhu, S. Pekarek, B. Fahimi, and B. J. Deken, "Investigation of force generation in a permanent magnet synchronous machine," IEEE Transactions on Energy Conversion, vol. 22, no. 3, pp. 557-565, Sept. 2007, doi: 10.1109/TEC.2006.888034.

[19] A. Chiba, T. Fukao, O. Ichikawa, M. Oshima, M. Takemoto, and D. G. Dorrell, Magnetic bearings and bearingless drives: Elsevier, Jan. 2005, doi: 10.1016/B978-0-7506-5727-3.X5000-7.

[20] L. Zhou and D. L. Trumper, "Reluctance force magnetic suspension characteristics and control for cylindrical rotor bearingless motors," Journal of Dynamic Systems, Measurement, and Control, vol. 139, no. 3, pp. 1-8, Jan. 2017, doi: 10.1115/1.4035007.

[21] F.-C. Lin and S.-M. Yang, "Analysis and modeling of the radial force in a switched reluctance motor with sinusoidal excitations," in The Fifth International Conference on Power Electronics and Drive Systems, 2003. PEDS 2003., Nov. 2003, pp. 938-943, doi: 10.1109/PEDS.2003.1283094.

[22] Q. M. Ali and M. M. E. Ali, "Direct Current Deadbeat Predictive Controller for BLDC Motor Using Single DC-Link Current Sensor," Engineering and Technology Journal, vol. 38, no. 8, pp. 1187-1199, Aug. 2020, doi: 10.30684/etj.v38i8A.471.

[23] M. Y. Bdewi, A. M. Mohammed, and M. M. E. Ali, "Design and Performance Analysis of Permanent Magnet Synchronous Motor for Electric Vehicles Application," Engineering and Technology Journal, vol. 39, no. 3A, pp. 394-406, March 2021, doi: 10.30684/etj.v39i3A.1765.

[24] S. Munisekhar, G. Marutheswar, and P. Sujatha, "The Fastest MPPT Tracking Algorithm for a PV array fed BLDC Motor Driven Air Conditioning system," in 2019 Fifth International Conference on Electrical Energy Systems (ICEES), Feb. 2019, pp. 1-5, doi: 10.1109/ICEES.2019.8719321.

[25] F. Wang, Y. Zhu, H. Wang, and D. Zhao, "Design and analysis of a bearingless permanent-magnet motor for axial blood pump applications," IEEE Access, vol. 8, pp. 7622-7627, Dec. 2019, doi: 10.1109/ACCESS.2019.2959633.

\section{BIOGRAPHIES OF AUTHORS}

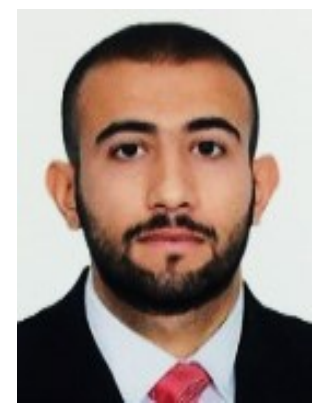

Ali A. Yousif (iD 81 SC P was born in Baghdad, Iraq in 1993. He received a Bachelor's degree in Electrical Engineering from University of the Technology, Iraq in 2017. He is currently studying toward a Master's degree of Science in Electrical Power Engineering at the University of Technology, Iraq. He can be contacted at email: eee.19.10@grad.uotechnology.edu.iq.

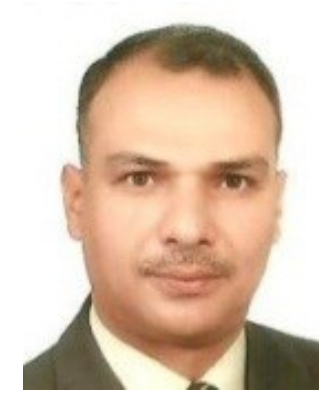

Ahmed M. Mohammed (iD SC $\mathrm{P}$ received the B.Sc. and M.Sc. degrees from the University of Technology, Baghdad, Iraq, in 1995 and 2006, respectively, both in electrical and electronic engineering. He received his Ph.D. degree in electrical engineering at The University of Nottingham, Nottingham, U.K. He can be contacted at email: ahmed.m.mohammed@uotechnology.edu.iq.

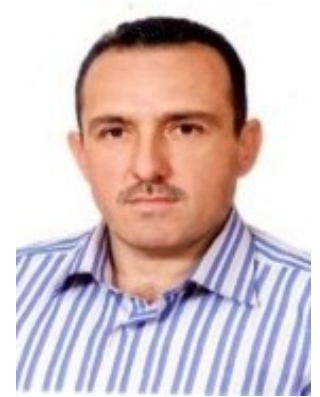

Mohammed Moanes E. Ali (D) SI SC P was born in Baghdad, Iraq in 1971. He received the B.Sc., M.Sc., and Ph.D. degrees in electrical engineering from University of Technology, Iraq in 1994, 1997, and 2009, respectively. Since May 2006, he has been with Department of Electrical Engineering-University of Technology, where he was an Assist. Lect., became a Lecturer in 2009, and an Assist. Prof. in 2018. His current research interests include Electro heat (induction heating), Electrical Machines, and Drives. Mohammed Moanes published more than twenty-four technical papers. $\mathrm{He}$ can be contacted at email: mohammedmoanes.e.ali@uotechnology.edu.iq. 